Pesq. Vet. Bras. 37(8):829-834, agosto 2017

DOI: $10.1590 / \mathrm{S} 0100-736 \mathrm{X} 2017000800008$

\title{
Intoxicação natural e experimental por Leucaena leucocephala em equinos ${ }^{1}$
}

\author{
Mirna R. Porto ${ }^{2}$, Augusto R.C. Moscardini ${ }^{3}$, Ernane P.F. Novais ${ }^{2}$, Sérgio L.S. Cabral \\ Filho $^{2}$, Eduardo M.M. Lima² e Márcio B. Castro ${ }^{2 *}$
}

\begin{abstract}
Porto M.R., Moscardini A.R.C., Novais E.P.F., Filho S.L.S.C., Lima E.M.M. \& Castro M.B. 2017. [Natural and experimental Leucaena leucocephala poisoning in horses.] Intoxicação natural e experimental por Leucaena leucocephala em equinos. Pesquisa Veterinária Brasileira 37(8):829-834. Laboratório de Patologia Veterinária, Faculdade de Agronomia e Veterinária, Universidade de Brasília, Av. L4 Norte, Asa Norte, Brasília, DF 70910-970, Brazil. E-mail: mbcastro@unb.br

This paper reports the main clinical changes of natural and experimentally poisoning by Leucaena leucocephala in horses. Outbreaks of poisoning occurred in São Paulo and Goiás States, where six horses after ingestion of bark and/or leaves of the plant showed alopecia mainly in mane and tail. The diagnosis was based on the observation of plant intake and clinical signs. In horses experimentally poisoned, clinical examination was performed and skin biopsies were taken from mane, back and tail regions, and triiodothyronine (T3) and thyroxine (T4) serum levels were assayed. Alopecia in mane and tail was the main clinical sign, accompanied by anorexia, weight loss and lethargy in all horses. T3 and total T4 showed significant decrease in serum levels $(p \leq 0.05)$ in the third week of leucaena intake compared with baseline levels. Marked telogenization of hair follicles at the end of the experiments were observed in skin biopsies. The clinical and pathological findings in poisoned horses are similar to those observed in ruminants. Experimental poisoning of horses by the plant highlights the marked decline in levels of thyroid hormones, suggesting goitrogenic effect of mimosine and its derived compounds, with transient hypothyroidism and alopecia due to accentuated reduction in follicular activity.
\end{abstract}

INDEX TERMS: Poisonous plants, Leucaena leucocephala, plant poisoning, alopecia, hypothyroidism, T3, T4, equine.

RESUMO.- Este trabalho investigou as principais alterações clínicas e dermatopatológicas de equinos intoxicados natural e experimentalmente por Leucaena leucocephala. Os surtos ocorreram nos estados de São Paulo e Goiás, onde seis cavalos após a ingestão de casca e/ou folhas de L. leucocephala apresentaram alopecia, principalmente na crina e cauda. Nesses animais o diagnóstico foi baseado na observação da ingestão da planta e dos sinais clínicos. Nos animais intoxicados experimentalmente, foi realizado o

\footnotetext{
${ }^{1}$ Recebido em 15 de janeiro de 2017. Aceito para publicação em 30 de março de 2017.

${ }^{2}$ Faculdade de Agronomia e Veterinária, Universidade de Brasília (UnB), Campus Darcy Ribeiro s/n, Av. L4 Norte, Asa Norte, Brasília, DF 70910970, Brasil. *Autor para correspondência: mbcastro@unb.br

${ }^{3}$ Médico Veterinário do Quadro de Oficiais de Saúde, Regimento de Polícia Montada do Distrito Federal, Granja Modelo Riacho Fundo, Riacho Fundo I, Brasília, DF 71805-731.
}

exame clínico, biópsias da pele das regiões de crina, dorso e cauda e foi feita dosagem sérica de tri-iodotironina (T3) e tiroxina (T4). Alopecia da crina e cauda foi o principal sinal clínico observado, seguido de anorexia, emagrecimento e apatia em todos os equinos. Os níveis de T3 e T4 total apresentaram redução significativa $(p \leq 0,05)$ na terceira semana de ingestão da leucena quando comparado aos níveis basais. As alterações histológicas observadas nas biópsias de pele demonstram acentuada telogenização dos folículos pilosos ao final dos experimentos. Os achados clínico-patológicos em equinos intoxicados são semelhantes aos observados em ruminantes. A intoxicação experimental de equinos por L. leucocephala evidenciou o acentuado declínio dos níveis dos hormônios tireoideanos, sugerindo efeito bociogênico da mimosina e seus compostos derivados, com hipotireoidismo transitório e alopecia devido à acentuada redução da atividade folicular. 
TERMOS DE INDEXAÇÃO: Plantas tóxicas, Leucaena leucocephala, intoxicação por plantas, leucena, alopecia, hipotireoidismo, T3, T4, equino.

\section{INTRODUÇÃO}

Leucaena leucocephala é uma leguminosa arbórea de ampla distribuição muito utilizada na alimentação de ruminantes nas regiões tropicais e subtropicais (Hammond 1995, Riet-Correa et al. 2004, Halliday et al. 2013). É uma planta de alto valor nutritivo, com alto índice protéico, de boa digestibilidade, perenidade e palabilidade, porém seu consumo exagerado pode levar a um quadro de intoxicação, acarretanto em prejuízos econômicos pela redução na produtividade ou pela morte dos animais (Jones et al. 1978, Almeida et al. 2006, Peixoto et al. 2008).

A intoxicação pela L. leucocephala ocorre quando seu consumo ultrapassa 30\% da alimentação diária (Holmes 1981, Halliday et al. 2013) e tem como princípio ativo o aminoácido não protéico denominado mimosina (Riet-Correa et al. 2004). A mimosina e seus principais metabólitos, 3,4-dihidroxipiridona (DHP) e 2,3-DHP, impedem a peroxidação do iodo na tireóide (iodação), diminuindo a síntese de T3 (tri-iodotironina) e T4 (tiroxina) (Jones et al. 1978, Halliday et al. 2013). 0 hipotireoidismo secundário à intoxicação reduz o metabolismo e a função de inúmeros sistemas, sendo a causa das apresentações clínicas (Jones et al. 1978).

A principal lesão associada à ingestão excessiva da planta é a alopecia, mas efeitos tóxicos menos frequentes também podem ocorrer como emagrecimento, ulcerações da língua e esôfago, atrofia de gengiva, sialorreia, bócio, infertilidade e até mesmo a morte (Jones et al. 1978, Luo et al. 2000, Riet-Correa et al. 2004, Almeida et al. 2006, Oliveira Jr et al. 2009). A alteração cutânea é caracterizada por acantose, hiperqueratose e atrofia da derme, com folículos pilosos em número e tamanho reduzidos, a maioria desses em fase telógena ou catágena (Luo et al. 2000, Riet-Correa et al. 2004, Almeida et al. 2006).

Ovinos, bovinos, caprinos são susceptíveis à intoxicação e correspondem pela maioria dos estudos e relatos (Riet-Correa et al. 2004, Almeida et al. 2006, Peixoto et al. 2008, Oliveira Jr. et al. 2009, Halliday et al. 2013). Em equinos, a intoxicação por L. leucocephala é praticamente desconhecida em todo o mundo, apenas com a descrição clínica de um caso de toxicidade natural pela planta em um animal no Brasil (Mullenax 1957, Oliveira Jr et al. 2009). 0 objetivo desse trabalho foi caracterizar os aspectos clínicos, dermatopatológicos e níveis de T3 e T4 na intoxicação experimental de equinos por L. lecocephala e descrever surtos de intoxicação natural na espécie.

\section{MATERIAL E MÉTODOS}

Esse trabalho consiste na investigação de surtos de intoxicações por Leucaena leucocephala e na descrição de intoxicações experimentais em equinos pela planta.

Três surtos de intoxicação por leucena em equinos foram investigados, sendo dois no estado de São Paulo (SP) e um no estado de Goiás (GO). Nesses casos o diagnóstico baseou-se na observação da ingestão da planta e no registro dos sinais clínicos observados.
Os dois surtos em SP ocorreram em duas propriedades distintas nos municípios de Santa Cruz do Rio Pardo e Ourinhos respectivamente. No primeiro deles, dois cavalos adultos, machos castrados, foram soltos em um piquete de L. lecocephala, cultivada com espassamento de $1 \mathrm{~m}$ entre fileiras e de $30 \mathrm{~cm}$ entre as covas, consorciada com Brachiaria humidicula. Na segunda propriedade em SP, a intoxicação ocorreu em um equino, adulto, macho castrado, devido à mudança de cerca, quando então, árvores de leucena que encontravam-se próximas a divisa do piquete, passaram a se localizar no interior do pasto de Brachiaria decumbens. 0 surto na cidade de Valparaíso de Goiás (GO) envolveu três equinos adultos (um macho e duas éguas), mantidos em área sem pasto formado e com muitas árvores da planta.

Em uma segunda fase, foram realizados dois experimentos de intoxicação pela planta em equinos. 0 primeiro experimento foi realizado entre fevereiro e março de 2007, no Hospital Veterinário de Grandes Animais da Universidade de Brasília, com duração de vinte e um dias. Três cavalos, sem raça definida, machos castrados, adultos $\left(A_{1}, A_{2}\right.$ e $\left.A_{3}\right)$, foram mantidos em baias de alvenaria com fornecimento controlado de folhas de L. lecocephala, na dose de $55 \mathrm{~g} / \mathrm{kg} /$ dia, divididos em dois fornecimentos diários e água à vontade. Os sinais clínicos foram registrados diariamente e as biópsias de pele colhidas antes do início (biópsia 1) e ao final do experimento (biópsia 2). As amostras de pele foram retiradas com a utilização de saca-bocado (punch) de $5 \mathrm{~mm}$ de espessura, sob anestesia local com lidocaína $2 \%$ sem vasoconstritor, fixadas em solução de formol $10 \%$ tamponado com fosfatos $\mathrm{pH} 7.0$, processadas rotineiramente para inclusão em parafina e coradas por hematoxilina e eosina para avaliação em microscopia de luz.

O segundo experimento ocorreu entre abril e maio de 2016, na Fazenda Água Limpa - UnB, com duração de 45 dias. Cinco equinos $\left(\mathrm{B}_{1}, \mathrm{~B}_{2}, \mathrm{~B}_{3}, \mathrm{~B}_{4}\right.$ e $\left.\mathrm{B}_{5}\right)$, machos e fêmeas, adultos, foram mantidos em piquete formado exclusivamente por L. leucocephala, cv. Cunningham, com a ingestão à vontade da planta, suplementados com $0,5 \%$ do peso vivo/dia de ração comercial para equinos e água ad libitum. Antes de iniciar o experimento, foram colhidas amostras de sangue por venopunção jugular para dosagem dos níveis séricos de T3, T4 total e T4 livre pelo ensaio não-radioativo de quimiluminescência (Singh et al. 1997), e durante o experimento, mensurados semanalmente. Os animais foram submetidos ao exame clínico duas vezes por semana.

As biópsias de pele foram realizadas e processadas de forma semelhante ao experimento 1 , nas regiões da crina (N), dorso (D) e cauda (C) em cada um dos animais no período pré-experimental (biópsia 1), com 15 dias (biópsia 2), 30 dias (biópsia 3) e 45 dias (biópsia 4) de ingestão da planta. Em ambos experimentos, foi realizada a contagem percentual de 50 folículos pilosos com objetiva de grande aumento microscópico (40X) nas biópsia de pele para a identificação das fases do ciclo do pelo (Mulinari-Brenner et al. 2006) em cada uma das regiões avaliadas.

As contagens percentuais das fases do desenvolvimento piloso por região e número da biópsia nos experimentos foram comparados pelo método ANOVA e teste de Tukey. A comparação das médias da atividade enzimática hormonal de T3, T4 livre e T4 total semanais foram determinadas com o método ANOVA e teste de Dunnett. Todas as analise foram realizadas com o programa PrismGraph for Windows 6.01.

\section{RESULTADOS}

Nas intoxicações naturais de equinos no estado de São Paulo foi constatada a ingestão de folhas e de casca de árvores de Leucaena leucocephala (Fig.1A) pelos animais, mesmo em condições de boa disponibilidade de pastagem (capim braquiária). Em Goiás, os equinos se alimentaram avida- 
mente de folhas da planta, pois havia escassez de forragem no piquete onde eram mantidos. Em todos os surtos de intoxicação pela leguminosa houve queda e rarefação dos

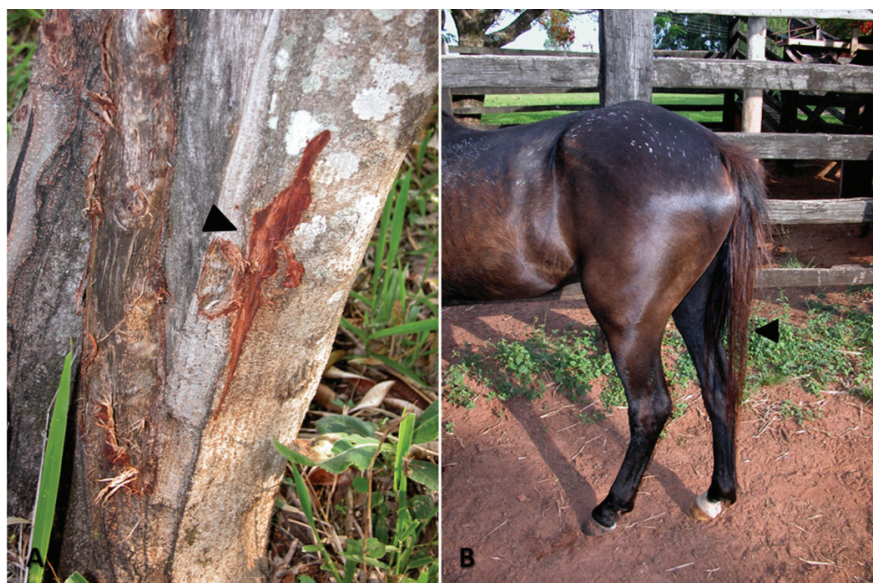

Fig.1. (A) Leucaena leucocephala, caule. Área recém-removida da casca por equinos em surto de intoxicação natural em São Paulo (cabeça de seta). (B) Equino, cauda. Rarefação pilosa (cabeça de seta) após um mês de ingestão de folhas e casca de Leucaena leucocephala.

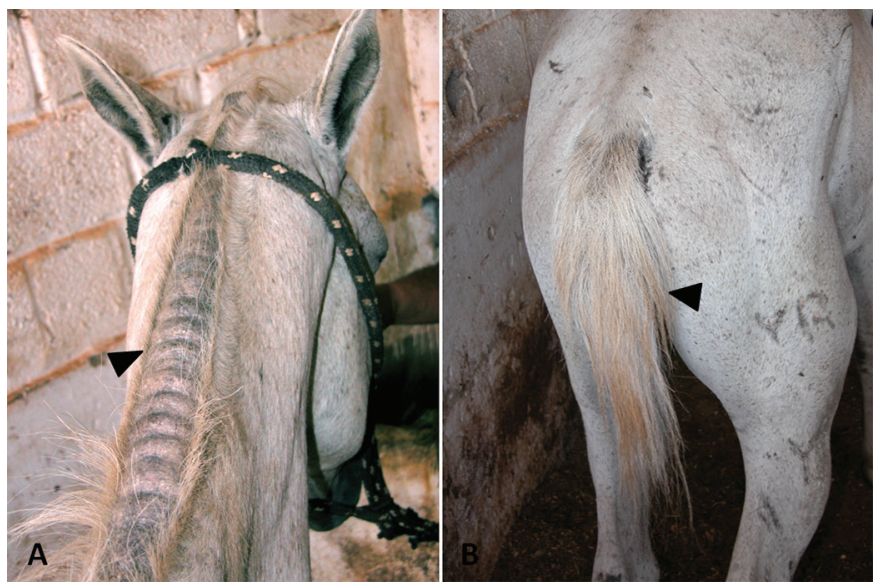

Fig.2. (A) Equino, crina. Alopecia acentuada (cabeça de seta) em animal após 20 dias alimentado exclusivamente com Leucaena leucocephala. (B) Equino, cauda. Rarefação pilosa marcada (cabeça de seta) em animal após 20 dias de alimentação exclusiva com L. leucocephala.

Quadro 1. Principais sinais clínicos em equinos com ingestão controlada (grupo A) e ingestão livre (grupo B) de Leucena durante o período experimental

\begin{tabular}{cccccccc}
\hline \multirow{2}{*}{ Equino } & \multicolumn{7}{c}{ Sinais clínicos } \\
\cline { 2 - 7 } & Apatia & Emagrecimento & Anorexia & A. Crina & A. Dorso & A. Cauda \\
\hline A1 & + & + & + & + & + & + \\
A2 & + & + & + & + & + & + \\
A3 & + & + & + & + & + & + & + \\
B1 & - & + & + & + & + & + & + \\
B2 & - & + & + & + & + & + \\
B3 & + & + & + & + & + & + \\
B4 & + & + & + & + & + & + \\
B5 & + & + & + & + & + & +
\end{tabular}

Sinais clínicos: $\mathrm{APT}=$ apatia, $\mathrm{EMG}=$ emagrecimento, $\mathrm{ANX}=$ anorexia, $\mathrm{ACR}$ = alopecia de crina, $\mathrm{ADR}=$ alopecia de dorso, $\mathrm{ACD}=$ alopecia de cauda.

- Ausência, + Presença.
Quadro 2. Percentual das fases de crescimento piloso em biópsias de pele de equinos com ingestão controlada (equinos A) e ingestão livre (equinos B) de Leucaena leucocephala durante o período experimental

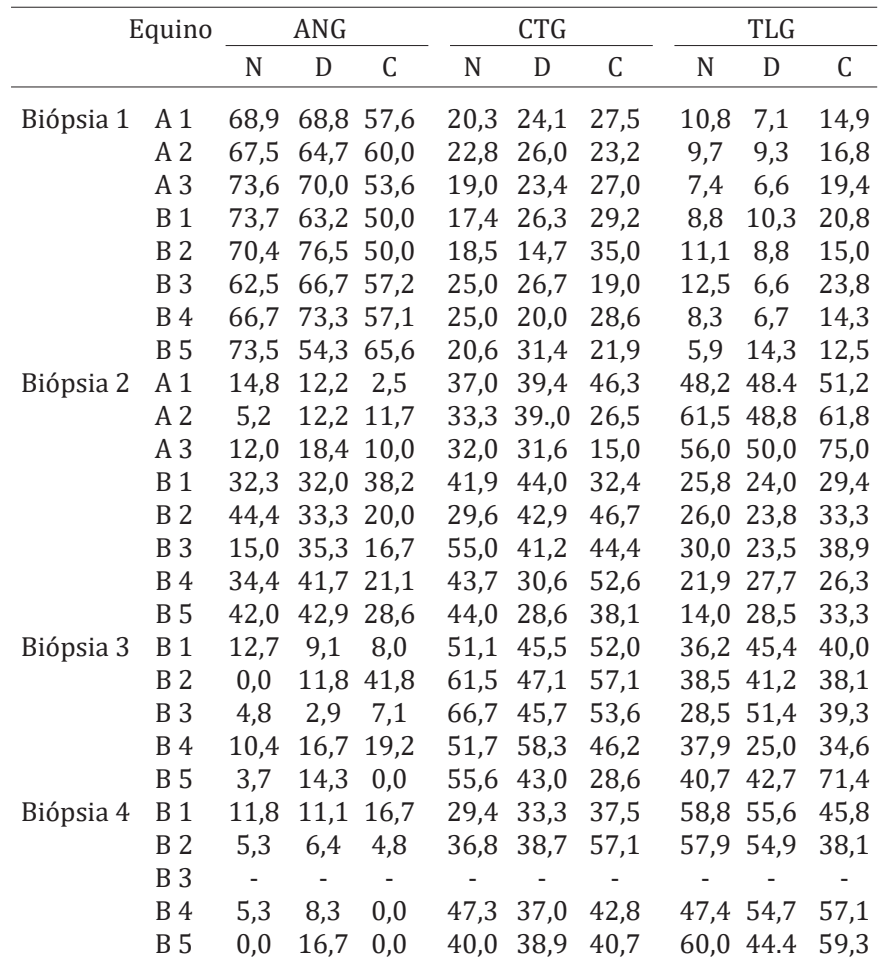

Fases do crescimento piloso: $\mathrm{ANG}=$ anágeno, $\mathrm{CTG}=$ catágeno, $\mathrm{TLG}=$ telógeno. Localização da biópsia: $\mathrm{N}=$ pescoço, $\mathrm{D}=$ dorso, $\mathrm{C}=$ cauda. Período de realização das biópsias: Biópsia 1 = período pré-experimental, Biópsia 2 = Equinos A com 21 dias de ingestão de Leucaena leucocephala. Equinos B com 15 dias de ingestão de L. Leucocephala, Biópsia 3 com 30 dias de ingestão de L. Leucocephala, Biópsia 4 com 45 dias de ingestão de L. leucocephala. - Não examinado.

pelos na crina, dorso e cauda (Fig.1B), aproximadamente após um mês da introdução dos animais nos piquetes contendo a planta.

As alterações clínicas observadas nos experimentos 1 e 2 encontra-se no Quadro 1. Nos três animais do primeiro experimento foi observado início de alopecia no 6으 dia de ingestão de leucena e essa queda se acentuou no 9으 dia, principalmente na crina (Fig.2A) e cauda que demonstrava aspecto de "cauda de rato" (Fig.2B). 0 animal A3 apresentou inapetência no $5^{\circ}$ dia de experimento e os animais A1 e A2 no $10^{\circ}$ dia.

No experimento 2, a queda de pelos foi observada primeiramente nos animais B3 e B5 na segunda semana, principalmente na crina. Na terceira semana, a alopecia se intensificou na crina e cauda dos animais B3, B4 e B5. Os animais B1 e B2 tiveram início de queda dos pelos na quarta semana do experimento, evoluindo para alopecia severa na quinta semana. Na sexta semana, todos os cinco animais apresentavam alopecia, com descamação da epiderme na crina e na cauda.

Nas biópsias de pele as alterações foliculares foram observadas em todos os animais dos experimentos (Quadro 2) e discreta hiperqueratose na epiderme. Todas as biópsias pré-experimento apresentaram a maioria dos folículos na fase anágena, alguns em catágeno e a minoria na fase 

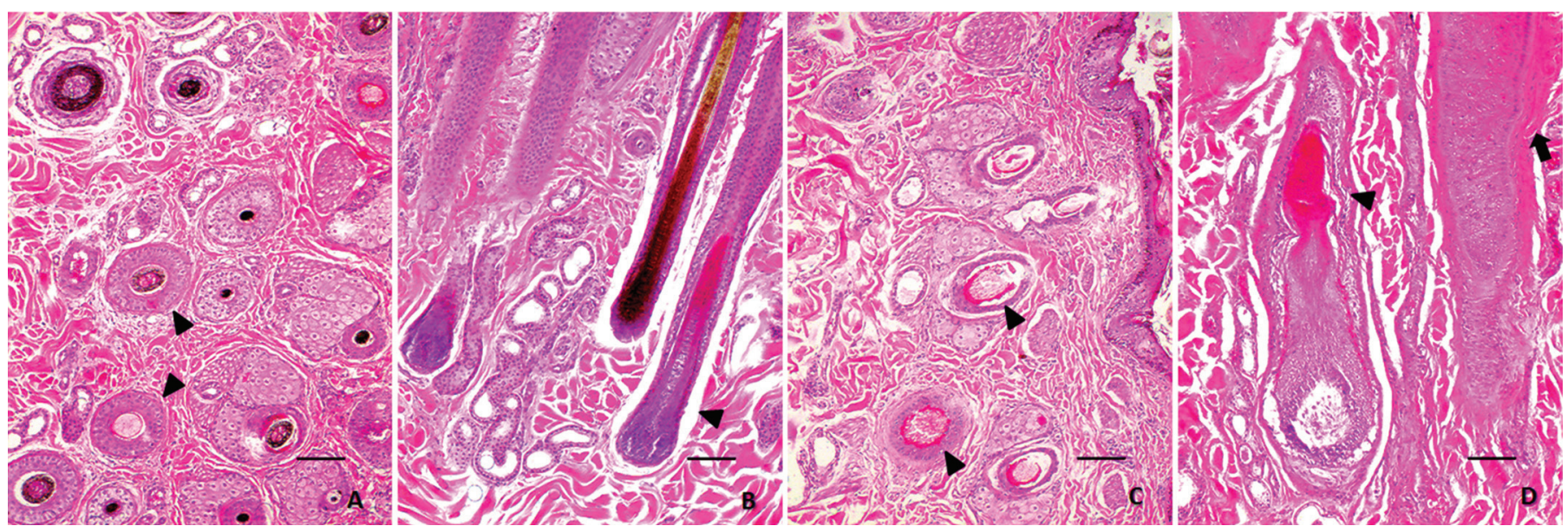

Fig.3. (A) Equino, pele, pré-experimento. Corte transversal de folículos pilosos com predomínio da fase anágena (cabeça de seta). (B) Equino, pele, pré-experimento. Corte longitudinal de folículo piloso em fase anágena (cabeça de seta). (C) Equino, pele, 60 dias de ingestão de Leucaena leucocephala. Corte transversal de folículos pilosos com acentuada telogenização, enrugamento da bainha radicular interna (cabeça de seta) e moderada atrofia folicular. (D) Equino, pele, 60 dias de ingestão de L. leucocephala. Corte longitudinal de folículos pilosos com acentuada telogenização (cabeça de seta) e espessamento da membrana basal (seta). HE, barra 100 $\mu$ m.
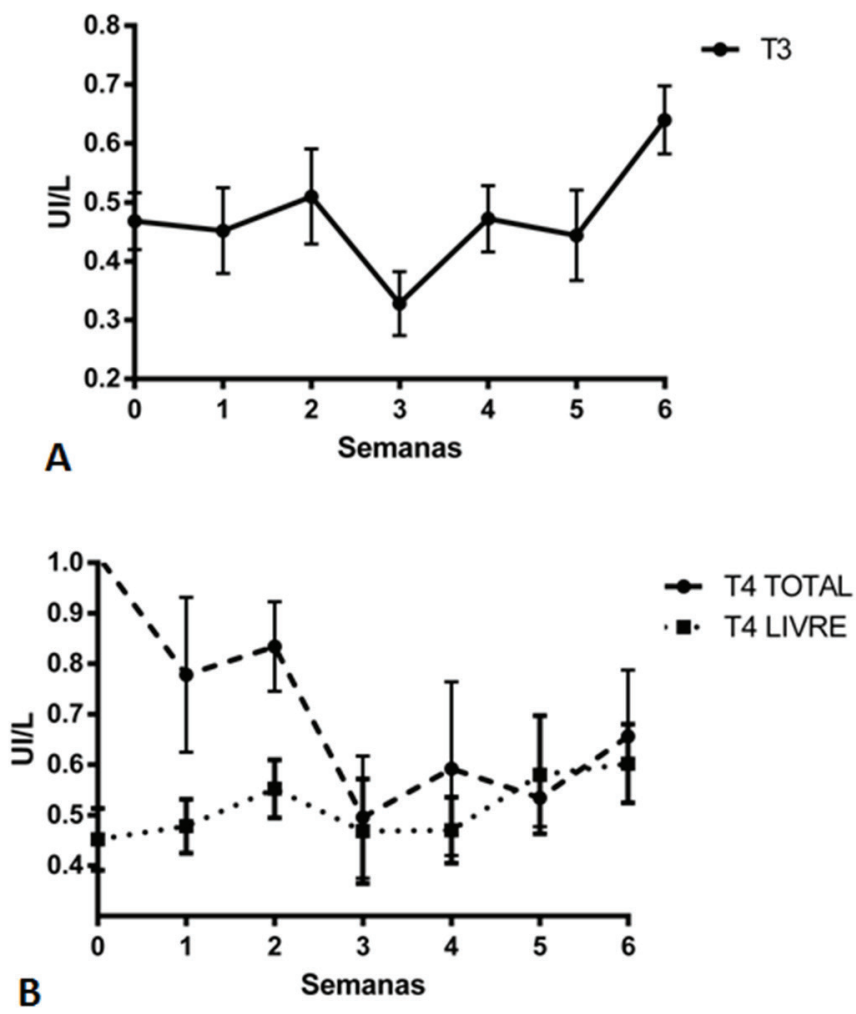

Fig.4. (A) Atividades séricas médias e erro padrão da média de T3 em equinos experimentalmente intoxicados por Leucaena leucocephala. Brasília, 2016. (B) Atividades séricas médias e erro padrão da média de T4 total e T4 livre em equinos experimentalmente intoxicados por L. leucocephala.

telógena $(\mathrm{p}<0,001)$. Ao final dos experimentos observou-se grande aumento no percentual de folículos telogenizados, na crina, dorso e cauda $(\mathrm{p}<0,01)$, e também o incremento percentual na fase de catágeno em comparação com as biópsias antes da ingestão da planta $(\mathrm{p}<0,01)$.

No experimento 2, o percentual de folículos em anágeno na fase pré-experimental foi maior que nas colheitas subsequentes (Fig.3A e B), atingindo os valores mais baixos aos 30 dias de ingestão da planta $(p<0,001)$ em todas as áreas cutâneas avaliadas. A alteração dermatopatológica mais marcante decorrente da alimentação de equinos com L. leucocephala foi o aumento marcante no percentual de folículos em telógeno (Figura 3C e D), seguido da fase catágena, gradativamente até 30 dias de experimento em relação às biópsias pré ingestão da planta na crina, dorso e cauda $(p<0,01)$. Em ambos experimentos a fase telogênica predominante na maioria dos folículos após a ingestão da planta, era caracterizada por acentuado enrugamento da bainha radicular interna, espessamento da membrana basal, queratinização do canal piloso e moderada atrofia folicular.

Os níveis séricos médios de T3 (Fig.4A) e T4 total (Fig.4B) apresentaram queda significativa $(p \leq 0,05)$ na terceira semana de ingestão de $L$. leucocephala quando comparados aos níveis basais. A mensuração do T4 livre apresentou elevação dos níveis a partir da quinta semana até o final do experimento (Fig.4B).

\section{DISCUSSÃO}

A ingestão natural e experimentalmente de Leucaena leucocephala demonstrou ser tóxica para equinos. 0 consumo da planta pelos grupos experimentais resultou em anorexia, emagrecimento e apatia na maioria dos animais, de forma semelhante ao observado em ruminantes que ingeriram experimentalmente grandes quantidades da planta (Holmes 1981, Hammond 1995, Almeida et al. 2006). Outros sinais relacionados à intoxicação por ingestão de leucena como, sialorreia, úlcera de língua e esôfago, catarata, bócio e morte (Jones et al. 1978, Holmes 1981, Riet-Correa et al. 2004, Almeida et al. 2006, Oliveira Jr et al. 2009) não foram observados nos animais avaliados nesse experimento. A razão para o surgimento dessas alterações clínicas são ainda desconhecidas, mas sugere-se que a anorexia possa ocorrer pela depleção dos hormônios tireoidianos ou devido às ulcerações de esôfago (Jones et al. 1978). 
A alopecia foi o sinal clínico mais evidente da intoxicação por L. leucocephala em equinos, manifestando-se de forma mais acentuada na crina e na cauda. 0 surgimento de alopecia variou entre 6 e 20 dias nos grupos experimentais, e após um mês de consumo da leguminosa nos casos de intoxicação natural. Esses achados nos equinos são similares aos observados em ovinos experimental e naturalmente intoxicados pela planta (Riet-Correa et al. 2004, Almeida et al. 2006). No primeiro relato da intoxicação espontânea de um equino no Brasil, o animal apresentou alopecia após 15 dias da ingestão da planta, em um período de escassez de pastagens e com ávida ingestão de folhas (Oliveira Jr et al. 2009). Os animais nos surtos de intoxicação natural estudados demoram mais tempo para apresentar alopecia em comparação aos equinos dos experimentos, possivelmente devido à ingestão de menores quantidades da planta ou variações na toxidez da planta.

$\mathrm{Na}$ intoxicação natural e experimental de equinos por L. leucocephala a alopecia ocorreu predominantemente na crina, dorso e cauda. A queda de pelos na crina e na cauda de equinos é considerada uma alteração característica da toxicose pela planta na espécie (Mullenax 1957, Oliveira Jr et al. 2009, Tokarnia et al. 2012). Bovinos intoxicados por L. leucocephala apresentaram como principais áreas alopécicas, o prepúcio, a cauda e a cernelha (Jones et al. 1978). Em ovinos com a toxicose, a alopecia é marcante na cabeça, pescoço e parte anterior do corpo (Riet-Correa et al. 2004, Almeida et al. 2006), em caprinos, na região lateral do corpo (Reis et al. 1998) e em coelhos, afeta a região inguinal, cauda e abdômen (Malafaia et al. 1994). Até o momento, é desconhecida a razão na variação entre os principais locais de alopecia nas espécies intoxicadas pela planta.

A mimosina é considerada o principal princípio tóxico da planta, porém a patogenia do efeito alopécico ainda não é bem definida. Essa substância tóxica é um aminoácido não protéico ( $\beta$-[N-(3-hidroxi-4-oxopiridil)] $\alpha$-ácido aminopropiônico), com efeito depilatório, não bociogênica e considerada responsável pelos sinas clínicos nos animais intoxicados (Tokarnia et al. 2012). A ação antimitótica da mimosina é capaz de inibir a síntese de DNA e de cisteína, afetando os folículos ativos e o crescimento de pelos pré-formados (Malafaia et al. 1994, Luo et al. 2000, Halliday et al. 2013). 0 efeito depilatório da leguminosa é evidente quando os níveis de mimosina na dieta são maiores que $0,015 \%$ do peso do animal (Halliday et al. 2013). Os achados nos equinos experimentalmente intoxicados reforçaram essas observações, onde os animais ingeriram quase exclusivamente a planta, diferentemente dos surtos onde o consumo da leguminosa era menor e associado à outras forragens.

Em ruminantes, a mastigação com saliva alcalina, e especialmente a incubação no rúmen, levam à degradação da mimosina para 3-hidroxi-4(1H)-piridina (3,4-DHP) (Hegarty et al. 1976, Megarrity \& Jones 1983), que, na presença de certos microrganismos ruminais, pode ser ainda convertido para o seu isômero 2,3-di-hidroxipiridina (2,3DHP) (Megarrity \& Jones 1983, Allison et al. 1989). Esse metabólito da mimosina é considerado o responsável pela ação bociogênica em animais que se alimentaram com a planta (Hegarty et al. 1976, Holmes et al. 1981, Halliday et al. 2013). Em herbívoros não-ruminantes, até o momento, não se conhece a formação de 3,4-DHP no ceco a partir da ingestão de mimosina. Entretanto, é possível especular que haja a transformação desse composto a partir da mastigação da planta e sua mistura com saliva, ou ainda, a formação em algum local do sistema digestório ainda não determinada (Malafaia et al. 1994).

Uma das alterações mais marcantes, e demonstrada de forma inédita, na intoxicação experimental de equinos por L. leucocephala cv. Cunninham (experimento 2), foi a queda significativa dos níveis séricos de T3 e T4 total na terceira semana de ingestão da planta. 0 período de maior redução desses hormônios ocorreu concomitantemente com a intensificação da queda de pelos. 0 2,3-DHP é capaz de afetar a produção de T4 devido ao seu efeito bociogênico em ovinos (Little \& Hamilton 1971), bovinos (Jones et al. 1978, Holmes 1981) e camundongos (Hegarty et al. 1976). Entretanto, a ingestão prolongada e exclusiva de $L$. leucocephala por bovinos causou o aumento da tiroxina, que poderia estar relacionado às flutuações da concentração de mimosina na planta nas diferentes estações do ano. (Holmes et al. 1981). Nos equinos, frente aos sinais clínicos observados, assim como em ruminantes, provavelmente ocorreu a formação do 2,3-DHP em algum local no trato digestório, que desencadeou as alterações hormonais, características da intoxicação por L. leucocephala nas outras espécies.

O metabólito primário da mimosina (3,4-DHP) atua devido à sua atividade antiperoxidase, inibindo a iodação da tirosina na etapa de ligação na tiróide. Este passo é crucial para a síntese de hormônios da tiróide (T3 e T4), resultando em redução sérica de níveis de T3 e T4 (hipotireoidismo), e assim, estimulando e aumentando os folículos tiroidianos (ação bociogênica) (Halliday et al. 2013). A carência ou inibição persistente da peroxidação de iodo e redução na produção dos hormônios tireoidianos, desencadeia o aumento compensatório da secreção de TSH, com hiperplasia das células foliculares da glândula tireóide e o surgimento do bócio coloidal (Rosol \& Gröne 2015).

Entre as alterações cutâneas observadas nas biópsias de pele dos equinos intoxicados pela planta nos experimentos, se destaca a marcada telogenização dos folículos pilosos e a acentuada redução no percentual de folículos em fase anagênica, que caracterizaram a ação depilatória da mimosina nesses animais. A infusão endovenosa de mimosina em caprinos de lã produziu acentuada diminuição da atividade folicular, com alopecia abrupta e temporária (Reis et al. 1998, Luo et al. 2000). Em ovinos experimentalmente intoxicados por L. leucocephala, houve alteração folicular em cordeiros caracterizada por acentuada telogenização folicular (Almeida et al. 2006). Coelhos alimentados exclusivamente com brotos frescos da planta apresentaram atrofia com hiperqueratinização de numerosos folículos, assim como a presença de folículos em fase telógena (Malafaia et al. 1994). As alterações foliculares observadas nos equinos experimentalmente intoxicados pela leguminosa demonstraram similaridade ao observado em outras espécies e possivelmente tenham a mesma gênese. 
A patogênese da alopecia na intoxicação pela planta não é bem elucidada, porém suspeita-se que a mimosina atue na fase anágena do folículo piloso e também iniba a enzima tirosina carboxilase, interferindo no crescimento folicular (Crounse et al. 1962). A mimosina pode reduzir a biossíntese de metionina em cistina durante a fase anágena do folículo piloso, resultando na parada do crescimento folicular (Hylin 1969). É importante também ser considerado que os equinos experimentalmente intoxicados por L. leucocephala apresentaram acentuada redução sérica de hormônios tireoideanos, que poderia indicar hipotireoidismo transitório, que afeta diretamente a atividades metabólica e mitótica de folículos em fase de crescimento ativo folicular (Douglas \& Douglas 2006).

O conjunto de experimentos e surtos de intoxicação natural por L. leucocephala em equinos, demonstra a susceptibilidade da espécie e reforçam a importância dessa toxicose no diagnóstico diferencial com outras enfermidades que causam alopecia. É importante diferenciar a intoxicação pela leguminosa de outras dermatoses alopécicas equinas como intoxicação por selênio, eflúvio piloso, reações imunológicas (atopia, alopecia areata, reações à drogas, etc), doenças infecciosas (dermatofilose e dermatofitose) e parasitárias.

\section{CONCLUSÕES}

O estudo da intoxicação por Leucaena leucocephala em equinos demonstrou que a ingestão natural e experimental da planta produz sinais clínicos nessa espécie, caracterizados principalmente pela alopecia no dorso, e mais acentuada na crina e cauda.

Experimentalmente, a ingestão excessiva da planta resulta no surgimento dos sinais clínicos mais precocemente e intensos que em casos naturais da toxicose.

Cavalos intoxicados pela planta apresentaram redução nos níveis séricos de T3 e T4 total, porém variação discreta nos valores de T4 livre. Os níveis menores desses hormônios foram observados na terceira semana de ingestão da leguminosa, coincidindo com o aumento na queda de pelos. Esses achados sugerem interferência no metabolismo tireoideano e efeito bociogênico similar ao observado em ruminates.

As principais alterações histológicas na pele de cavalos intoxicados por L. leucocephala são a acentuada telogenização folicular e a marcada redução dos folículos em fase anágena. Essas manifestações patológicas justificam a marcante queda de pelos proporcionadas pela ingestão da planta.

Novos estudos com a intoxicação pela leguminosa em equinos precisam ser realizados para elucidar os mecanismos fisiopatológicos envolvidos na alopecia, na redução de hormônios tireoideanos e na formação do princípio tóxico 3,4-DHP em herbívoros monogástricos.

Agradecimentos.- À Secretaria de Agricultura do Distrito Federal pela doação dos equinos para os expeimentos e ao Laboratório Santè, Brasília pela execução dos exames laboratoriais.

\section{REFERÊNCIAS}

Allison M.J., Hammond A.C. \& Jones R.J. 1990. Detection of ruminal bacteria that degrade toxic dihydroxy-pyridine compounds produced from mimosine. Appl. Environ. Microbiol. 56:590-594.
Almeida A.P.M.G., Kommers G.D., Nogueira A.P.A., Júnior L.G.B., Prado Marques B.M.F. \& Lemos R.A.A. 2006. Avaliação do efeito tóxico de Leucaena leucocephala (Leg. Mimosoideae) em ovinos. Pesq. Vet. Bras. 26:190194.

Crounse R.G., Maxwell J.D. \& Blank H. 1962. Inhibition of growth of hair by mimosine. Nature 194:694-695.

Douglas N.A. \& Douglas C.R. 2006. Fisiologia da glândula tireóide, p.10431061. In: Ibid. (Eds), Tratado de Fisiologia Aplicada às Ciências Médicas. 6 a ed. Guanabara Koogan, Rio de Janeiro.

Halliday M.J., Padmanabha J., McSweeney C., Kerven G. \& Shelton H.M. 2013. Leucena toxicity: a new perspective on the most widely used forage tree legume. Trop. Grassl. Forraj. Trop. 1:1-11.

Hammond A.C. 1995. Leucaena toxicosis and its control in ruminants. J. Anim. Sci. 73:1487-1492.

Hegarty M.P., Court R.D., Christie G.S. \& Lee C.P. 1976. Mimosine in Leucaena leucocephala is metabolized to a goitrogen in ruminants. Aust. Vet. J. 52:490.

Holmes J.H.G. 1981. Toxicity of Leucaena leucocephala for steers in the wet tropics. Trop. Anim. Health Prod. 13:94-100.

Holmes J.H.G., Humphrey J.D., Walton E.A. \& O'Shea J.D. 1981. Caracts, goitre and infertility in cattle on an exclusive diet of Leucaena leucocephala. Aust. Vet. J. 57:257-261.

Hylin J.W. 1969. Toxic peptides and a mino acids in foods and feeds. J. Agric. Food Chem. 17:492-496.

Jones R.J., Blunt C.G. \& Nurnberg B.I. 1978. Toxicity of Leucaena leucocephala: effect of iodine and mineral supplements on penned steers fed a sole diet of leucaena. Aust. Vet. J. 54:387-392.

Little D.A. \& Hamilton R.I. 1971. Leucaena leucocephala and thyroid function of newborn Lambs. Aust. Vet. J. 47:457-458.

Luo J., Litherland A.J., Sahlu T., Puchala R., Lachica M. \& Goetsh A.L. 2000. Effects of mimosine on fiber shedding, follicle activit, and fiber regrowth in Spanish goats. J. Anim. Sci. 78:1551-1555.

Malafaia P., Armien A.G. \& Peixoto P.F.V. 1994. Intoxicação por Leucaena leucocephala (Leg. Mimosoideae) em coelhos. Pesq. Vet. Bras. 14:105109.

Megarrity R.G. \& Jones R.J. 1983. Toxicity of Leucaena leucocephala in ruminants: the effect of supplemental thyroxine on goats fed on a sole diet of leucaena. Aust. J. Agric. Res. 34:791-798.

Mullenax C.H. 1957. A dietary cause of hair loss in Bahamian livestock. J. Am. Vet. Med. Assoc. 131:302.

Mulinari-Brenner K., Neto J.F., Souza F.H.M. \& Torres L.F.B. 2006. Avaliação quantitativa em cortes histológicos transversais do couro cabeludo. An. Bras. Dermatol. 81:227-32.

Oliveira Jr L.A.T., Fregona M.G., Souza V.R.C., Fernandes W.R. \& Coelho C.S. 2009. Intoxicação natural por leucena (Leucaena leucocephala) em um equino. Ciênc. Vet. Trop. 12:55-59.

Peixoto P.V., França T.F. \& Cunha B.M. 2008. Intoxicação espontânea por Leucaena leucocephala em uma cabra, no Rio de Janeiro, Brasil. Ciência Rural 38:551-555.

Riet-Correa F., Barros S.S., Araújo J.A.S., Vasconcelos J.S. \& Medeiros R.M. 2004. Intoxicação por Leucaena leucocephala em ovinos na Paraíba. Pesq. Vet. Bras. 24(Supl.):52.

Reis P.J., Puchala R., Sahlu T. \& Goetsch A.L. 1999. Effects of mimosine and 2,3-dihydroxypyridine on fiber shedding in Angora goats. J. Anim. Sci. 77:1224-1229.

Rosol T.J. \& Gröne A. 2015. Thyroid gland, p.310-336. In: Grant M.M. (Ed.), Jubb, Kennedy \& Palmer's Pathology of Domestic Animals. Vol.3. 6th ed., Elsevier Inc., St Louis, Missouri.

Singh A.K., Jiang Y., White T. \& Spassova D. 1997. Validation of nonradioactive chemiluminescent immunoassay methods for the analysis of thyroxine and cortisol in blood samples obtained from dogs, cats, and horses. J. Vet. Diagn. Invest. 9:261-268.

Tokarnia C.H., Brito M.F., Barbosa J.D., Peixoto P.V. \& Döbereiner J. 2012. Plantas que afetam o funcionamento do coração, p.27-37. In: Ibid. (Eds), Plantas Tóxicas do Brasil. $2^{\mathrm{a}}$ ed. Helianthus, Rio de Janeiro. 